\title{
Piloting a safe spaces, asset-building program for adolescent girls in urban Ghana
}

Sarah Engebretsen

Population Council

Selina F. Esantsi

Population Council

Follow this and additional works at: https://knowledgecommons.popcouncil.org/departments_sbsr-pgy

Part of the Demography, Population, and Ecology Commons, Family, Life Course, and Society Commons, Gender and Sexuality Commons, International Public Health Commons, and the Medicine and Health Commons How does access to this work benefit you? Let us know!

\section{Recommended Citation}

Engebretsen, Sarah and Selina F. Esantsi. 2011. "Piloting a safe spaces, asset-building program for adolescent girls in urban Ghana," Promoting Healthy, Safe, and Productive Transitions to Adulthood Brief no. 40. New York: Population Council. 


\section{Piloting a safe spaces, asset-building program for adolescent girls in urban Ghana}

\section{Prepared by Sarah Engebretsen and Selina Esantsi}

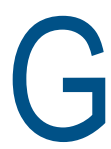
hana's population of 24 million is projected to reach 31.8 million in 2025-a 32 percent increase over 15 years (PRB 2010). This population growth is coupled with rapid urbanization as people move to large cities, including Accra and Kumasi. While migration to an urban area often presents new opportunities, urban life can be quite bleak for adolescent girls. Urban adolescent females experience a rapid decline in school enrollment, often because they need to provide economic support to families. While school enrollment stands at 92 percent for 11-year-old urban females, it declines to 51 percent by age 17 (Population Council 2010). Furthermore, nearly 4 percent of urban 10-14-year-old females are not in school and not living with either parent (Population Council 2010). Girls living apart from families and out of school often lack social networks and have few opportunities to build critical skills needed for adulthood. Acquisition of such skills is important for Ghana's development given its increasingly young population, 39 percent of which is below the age of 15 (PRB 2010).

The Population Council has a global portfolio of work reaching vulnerable adolescent girls. Although each program is context-specific, all provide a safe, girl-specific platform where adolescent girls can develop core skills, form friendships, receive and give peer support, increase their social networks, and receive mentoring from trusted adults who can serve as girls' advocates (Brady 2003). The Council drew upon experience from a community health project in Accra to select the appropriate site for a pilot project with adolescents in urban Ghana.

In 1999, Ghana Health Service adopted a model for communitybased health service delivery based on the Population Council's ex-

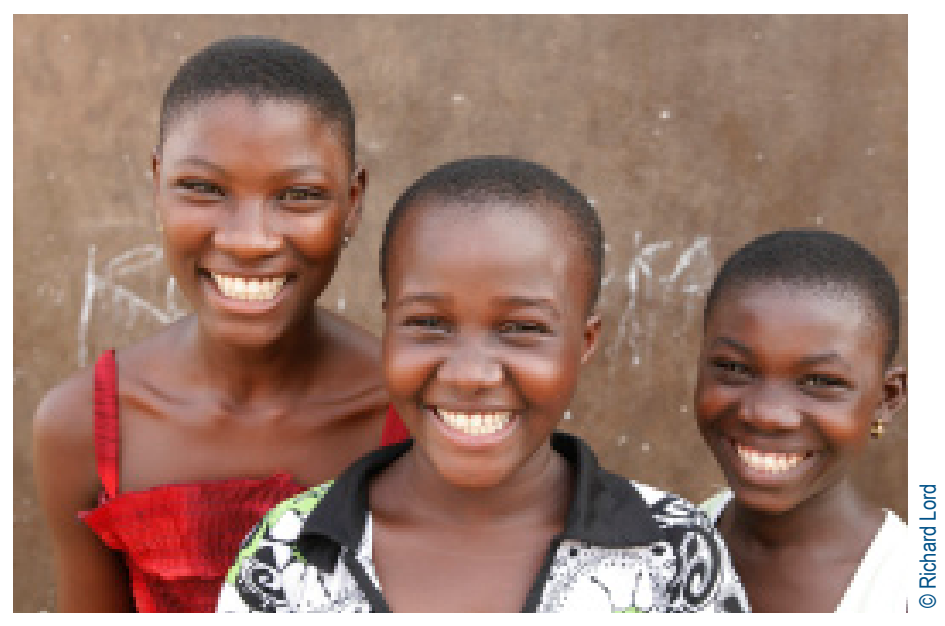

tensive work in Navrongo and Nkwanta. Known as Community-based Health Planning and Services (CHPS), this initiative aimed to provide clinical health care for women and children as well as easily accessible family planning services.

Initially designed as a rural program, CHPS was later piloted in two urban communities in the Greater Accra region: U-Compound in Tema Municipality and Glefe in Accra Metropolis. Tema Municipality is a large port, and U-Compound is a fishing community located on the water. The livelihood of U-Compound residents depends on catching fish and selling them in markets to merchants working in Tema. CHPS data from U-Compound reveal that this densely populated urban settlement has a population of 3,585 who live in makeshift buildings and suffer from poor sanitation. Experience in urban CHPS demonstrated that adolescents in U-Compound were lacking knowledge in sexual and 
reproductive health and were not accessing available services. Parents grew concerned about pregnancy, but did not feel equipped to address sexual and reproductive health issues with their daughters. Given the needs of adolescents in Tema Municipality and the Council's experience in this informal urban settlement, U-Compound was selected as a site for a pilot program on building the health, social, and economic assets of adolescent girls.

\section{Working with the community in the pre-implementation phase}

In the months leading up to the program launch, the project team met with stakeholders including government officials from Ghana Health Service, the Tema Municipal Health Management Team, the Ministry of Women and Children, and the Ministry of Employment and Social Welfare. Consultations also took place with community health officers and volunteers from the urban CHPS compound, elders from ethnic groups represented in U-Compound, and the chief of Tema. The meetings with these individuals were instrumental in the community entry process. A durbar (community awareness session) was held to introduce the program and engage community members-specifically parents, elders, community leaders and teachers, and girls-in discussions to seek their input on the needs of adolescent girls in U-Compound. Discussions revealed the need to put a program in place where trusted female role models would teach adolescent girls about sexual and reproductive health and other important information required for healthy transitions to adulthood. Young female leaders were then selected to serve as program mentors. Careful attention was given to selecting mentors who were from the intervention site and slightly older than the target population, so that girls in the program would identify with them and would feel comfortable approaching them for advice. The mentors were trained to promote girls' health and their social and economic assets using a flexible and demand-driven curriculum. While the curriculum has structured content, the mentors also learned how to adapt the sessions to the interests and abilities of the girls.

Community discussions revealed the need to have community representatives serve as a link between program mentors and the larger community. The program team established the role of community mothers and selected four women who command the respect of girls and other community members. Community mothers are responsible for mediating potential problems that arise as a result of a girl's participation in the program and for following-up with families if a girl stops attending the program.

Recruitment was conducted with input from elders, community health officers, and community health volunteers. These stakeholders helped to identify girls in the target group: aged 12-15. Because UCompound is a small informal settlement, the project team was able to go door-to-door to identify households with members who met selection criteria. Informed consent was sought from interested girls and their parents, and intake interviews were conducted with program participants. Questions used in these interviews addressed knowledge, attitudes, and behaviors related to social capital, education, life skills, health, sexual and reproductive health, and girls' aspirations for the future.

The next step was finding a space within the community where girls groups could meet. It is important to have a space where girls feel safe and have some level of privacy so that they feel comfortable expressing themselves and discussing their lives with other adolescent females. The project team began by doing a participatory mapping exercise with the girls to assess their perceived safety in various places in the community. The girls expressed concern that designated public spaces-such as community sheds-were frequented almost exclusively by men and were not entirely safe for girls. The girls

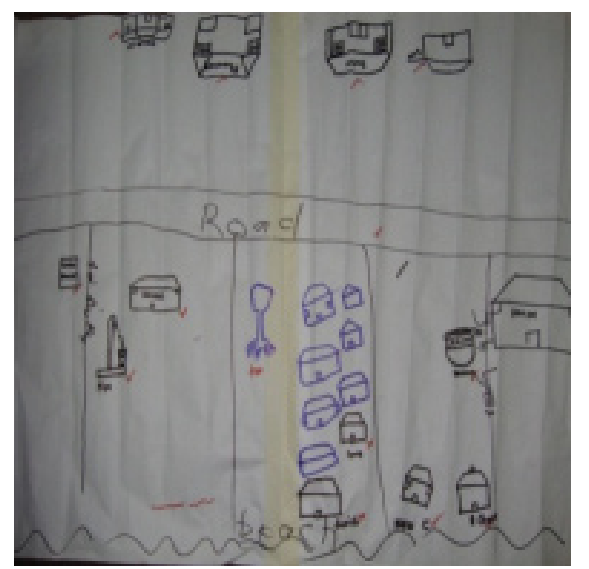

Using participatory mapping, the girls identified safe and unsafe spaces in their community. reported feeling very safe in churches and schools. Discussions were held with the headmaster of the community school, who offered an unoccupied room within the school for program from the community spent a day cleaning this space and decorating it so that they could feel ownership over a girls-only space. use. Adolescent girls

\section{A pilot program to promote financial, health, and life skills among urban adolescent females}

In late 2009, the Population Council launched a pilot intervention for adolescent girls in U-Compound. This pilot program aims to test the feasibility of launching a safe spaces asset-building intervention in urban Ghana. Specifically, the pilot is meant to determine the possibility of engaging girls and their community in this type of program, finding experienced female leaders from within the community, and designing a multi-disciplinary program to meet the needs of program beneficiaries. While traditional interventions for youth are often knowledge-based reproductive health programs, this project team sought to establish a broad-based intervention that builds the health, social, and economic assets of adolescent girls.

The 90 adolescent females meet twice weekly in groups of 20 to 25 girls. Sessions are led by female mentors and focus on developing core skills in the following domains: life skills, general health, sexual and reproductive health, and financial capabilities. Concurrent with 


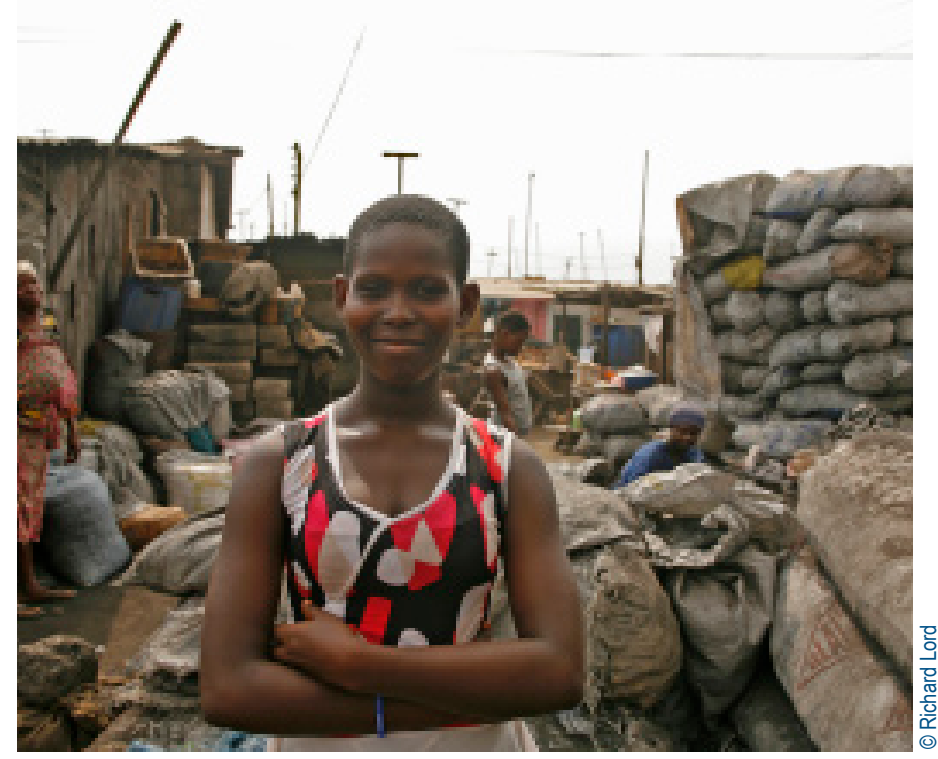

Recruitment for the program involved door-to-door visits in the community to identify eligible 12-15-year-old girls.

\section{Community perspectives on the program}

"Through the financial education lessons, I now understand the importance of saving, and with the assistance of one of our mentors I have opened an account at the bank. I am saving towards my education. I want to be a nurse in the future."

\section{-Program participant}

"I have made new friends and I now understand how my body functions. All my friends had their first menses months ago and I was worried that I had a problem. But now I know we all have it at different times and mine will start soon."

\section{-Program participant}

"Since my girl started the program, l've noticed that she informs me or asks permission whenever she is going out. Before the program she wasn't doing that."

\section{-Mother of program participant}

"I think the program is doing a good job with the girls. They are becoming more conscious of their actions. They seem to enjoy the sessions and are always in a hurry to attend them."

-Community elder this curriculum, girls are introduced to relevant services and resources within their community. The girls learn about self-esteem and selfidentity during the life-skills session and receive program identification cards. These cards help girls recognize themselves as citizens and encourage them to seek further documentation that may allow them to access social entitlements. During the health sessions, program participants visit the community health compound to learn about important health information and services available to them. Additionally, the girls visit a local business during the session on financial capabilities to learn about income-generating opportunities available in their community.

This pilot program partners with Right to Play ${ }^{\odot}$, which uses physical activity to provide key information to young people. Program mentors are trained in activities and games that develop leadership and cooperation skills in conjunction with health education. The mentors incorporate many of these activities into their sessions with the girls groups, and initial feedback has been very positive, particularly because adolescent females in U-Compound otherwise have limited opportunity for recreational activities.

For the duration of the pilot phase, the project team will assess which aspects of the program are working well, and where improvements ought to be made before expanding the program to a larger group of girls. The results of this evaluation will be shared with the community and will inform the design of the program's next phase.

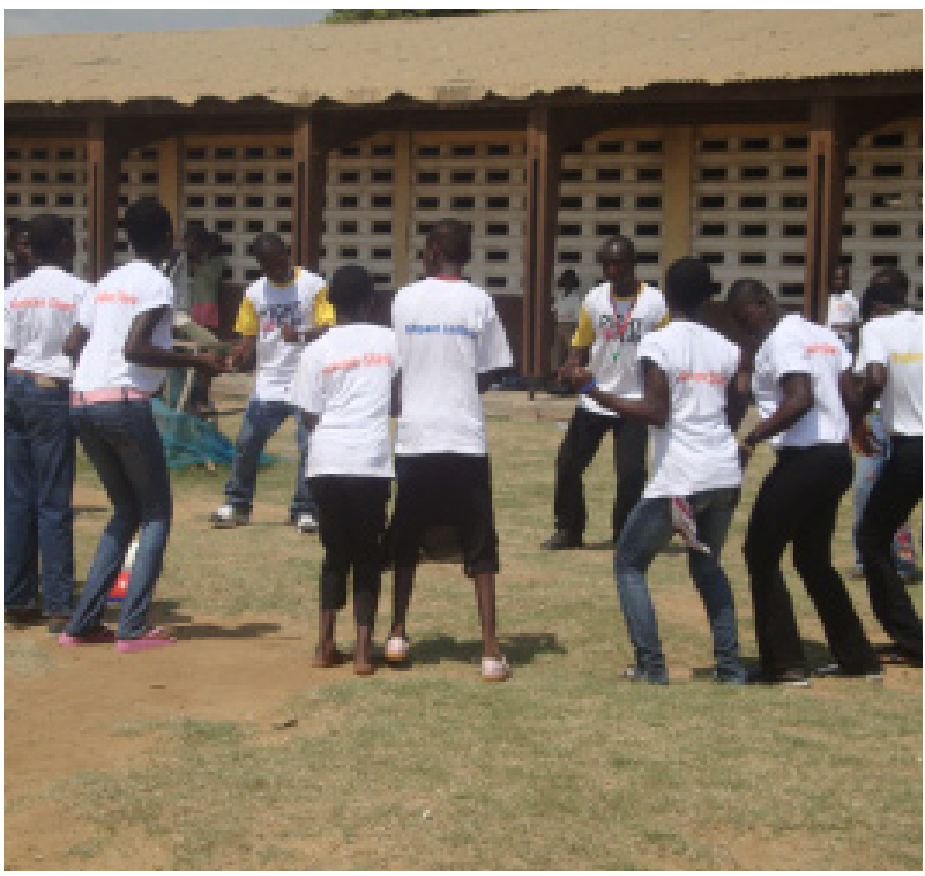

Right to Play ${ }^{\circ}$ encourages girls to participate in activities and games that develop leadership and cooperation skills in conjunction with health education. 
Initial observations from the pilot have shown that parents often prioritize boys' schooling over girls', and adolescent females are often removed from school in order to earn money in the informal sector. This school-leaving is concurrent with onset of puberty for girls. Therefore, in the next phase of this project, the intervention team aims to work with 10-13-year-old girls. This shift will allow for building girls' assets before they enter a critical period of developmental change.

\section{References}

Austrian, Karen and Dennitah Ghati. 2010. Girl Centered Program Design: A Toolkit to Develop, Strengthen and Expand Adolescent Girls Programs. New York: Population Council.

Brady, Martha. 2003. "Chapter 7-Safe spaces for adolescent girls," in Adolescent and Youth Sexual and Reproductive Health: Charting Directions for a Second Generation of Programming - Background Document for the Meeting. New York: UNFPA, pp.155-176.
Population Council. 2010. "The Adolescent Experience In-Depth—Using Data to Identify and Reach the Most Vulnerable Young People: Ghana 2008." New York.

Population Reference Bureau (PRB). 2010. "2010 world population data sheet." Washington, DC. <http://www.prb.org/Publications/ Datasheets/2010/2010wpds.aspx>. Accessed 6 May 2011.

\section{Donors}

UK Department for International Development

\section{Partner Institutions:}

Right to Play ${ }^{\odot}$

Ghana Health Service

\section{Population Council}

The Population Council changes the way the world thinks about critical health and development issues. We seek to understand the causes and consequences of gender inequality and the disparities in opportunity that arise during adolescence. We provide the evidence for better on-theground programs and policies that ensure successful and productive transitions to adulthood in developing countries. www.popcouncil.org

(c) 2011 The Population Council, Inc. 